system of dry land (such a system was rather an extensive archipelago than a continuous continent); this last was again divided into two systems : an Arctic and Occidental one, comprising North America, together with the northern parts of Asia and Europe, and an Indian one, communicating with South Europe. The former was the home of the Cervidæ, the rhinoceroses and most other Perissodactyls, the latter that of the Cavicorns and elephants. Very few mammals of Indian origin migrated into America; much more from the Arctic system into India. The same seems to be the case for ants. Myrmecina is perhaps the only North American genus of Indian origin (Tetramorium ccespitum being doubtless introduced by man), whereas a number of American-Arctic genera, sub-genera and species-groups, as Myrmecocystus, Messor, Myrmica, Camponotus pennsyluanicus, \&c., are more or less far diffused in India and Africa, Myrmica reaching Borneo, and Messor the Cape of Good Hope.

In Europe, the study of the Baltic and Sicilian amber proves that the Arctic fauna went down from the north, as a host of conquerors, invading the territory formerly occupied by other people. I believe that, in Miocene times the North American fauna was much like the actual cosmopolite and Arctic part of the recent fauna, and might have included a number of forms actually extinct. As in the Pliocene a bridge was put between North and South America, an invasion of neotropical forms took place, walking from south to north. But it is not improbable that other forms migrated in the opposite sense, and descended from North America into the neotropical region. I suppose that such was the case for the genus Pogonomyrmex, perhaps also for Dorymyrmex, Forelizus, and several species of Camponotus. It is not improbable that other genera from North America migrated southward, and later became extinct in their primitive home. The recent work of Mr. Scudder on Tertiary Curculionidae of North America seems to confirm this view, some of these fossil beetles belonging to genera now living only in South America. It is probable that a number of insects, actually regarded as typical members of the neotropical fauna, immigrated from North America, as it is proved by palæontology for several mammals, as, for instance, the llama and alpacca of the Pampas.

The North American origin of some South American ants was suggested by Prof. H. von Jhering, ${ }^{1}$ in a paper published last year. The author endeavours to sustain, by the study of the ants, his theory of the multiple origin of actual neotropical fauna. I agree in many points with him, 2 but I must recognise that the Formicide afford but little evidence in favour of his views. Actually, the ants of South America are distributed chiefly in relation to the climate and vegetation, no strong obstacles being put to the wide dissemination of the species, some of which range from Central America or from Mexico to Paraguay and Rio Grande do Sul. Chili is, however, an isolated country, which we may call " a continental island," although it is not surrounded by water. If we should take the Chilian fauna as a standard for the primitive fauna of v. Jhering's Archiplata, that should have been a very poor one, like the fauna of New Zealand, with which it offers a striking resemblance. The most characteristic feature of the Chilian ant fauna is the occurrence of peculiar species of Monomorium, like those inhabiting Australia and New Zealand, and of the genus Melophorus, found only in Australia and New Zealand. These facts corroborate the hypothesis of a Cretaceous or Eocene connection between South America and Australia.

New Zealand appears as a bit of old Australia, quite free from later Papuan or Indian intrusions, like Madagascar, which, as an isolated part of old Africa, has received but a few immigrants, when, at the Pliocene epoch, a stream of Indian life entered into the Athiopian continent. Probably Chili may be considered as a part of ancient Archiplata, secured from Guyanean and Brazilian immigrants by the heights of the Cordillera, but having preserved only an incomplete set of the original Archiplatean fauna.

I state these facts for the purpose of making the main conclusions of a special work known to a wide public. Exact knowledge of the exotic faunæe, and especially of the fossils, may enable us in future to carry further these incomplete and in part hypothetical results. Similar studies made on single groups of animals and plants by specialists, which do not only accumulate

1 H. von Jhering. "Die Ameisen von Rio Grande do Sul." (Berliner entomolog. Zeit. 39 Bd. I894. Pp. $321-446.1894$.

$z$ Othier points of $\mathrm{v}$. Jhering's theories, which I cannot accept, refer chiefly to the origin and antiquity of island faune. In these points I think that Wallace's views are right.

NO. I 347 , VOL. 52$]$ by blind statistical work names of families, genera, and species, but deal with them, knowing the value of each, are highly desirable. Summarising and integrating the single results will build up an exact knowledge of palæogeography, and of the origins and interrelations of the faunæ and floræ of the world.

C. EMery.

\section{A NEW FILM HOLDER.}

$\mathrm{NO}$ outdoor photographer can take a rough survey of the past few years without feeling some astonishment at the rapid progress made in nearly every branch of his art. The amateur is no doubt indirectly responsible for much of this advance; for it is through him that other brains have been set to work to satisfy all his many and various wants, in the way of instruments and accessories, to lighten his task at every step.

The camera, which a few years back was a heavy, clumsy and awkward instrument, is now of a light and handy construction, capable of being used in many cases without the tripod. Stops are now more generally of the Iris type, thus eliminating all possibilities of loss or of leaving them behind; while plateholders are now supplied capable of holding a dozen or more plates, and necessitating the use of only one dark shutter.

The introduction of the film has brought us, however, into a new era ; but the full benefit of this improvement can only be best appreciated by those who make use of their cameras while travelling.

Hitherto it has been impossible to make satisfactory use of the enormous advantages of celluloid flat films over glass plates; but now we have before us a holder which seems to give satisfaction, and which should prove a boon to photographers in general

A holder to be really efficient should be readily adaptable to any ordinary camera; it must contain a large quantity of films,



FIG. I.-Magazine and receiver, separated.

and when complete and loaded should not be any larger or heavier than the three double backs (lighter if possible); and, finally, should be provided with some means of swiftly and automatically changing the positions of the exposed films.

Such a holder, if simple and of moderate price, would be much sought after by the photographic world. A very near approach to such an ideal film-holder will be found in that known as the "Frena," of which a short description follows.

Fig. I gives a complete view of the holder (the two parts are here shown separately), ready to be fitted to any camera. It consists of two parts : the magazine $(\mathrm{M})$ and the receiver $(\mathrm{R})$, each of these parts being about half as thick again as an ordinary dark slide. The exposure is made in precisely the same way as with an ordinary dark slide, namely, by inserting the magazine in the slide rails of the camera, and by withdrawing, and subsequently replacing, the shutter of the magazine.

The film changing is brought about simply by folding the magazine and receiver together until they interlock, drawing out the two shutters, pressing a change button to one side, and pushing the shutters back again.

The exposed films, stored in the receiver, may then be removed for development one by one, or as a complete pack, just as the operator desires.

An automatic counter upon the back of the magazine shows at a glance how many pictures have been taken.

The peculiarity of these films is that their edges are notched, and in their packing an alternate sequence is maintained as regards the position of these notches. 
The films are supplied ready packed and arranged in the order in which they are to be inserted into the magazine.

To understand more clearly the position of the notches, it is best to take the empty magazine in hand, and entirely withdraw the black exposing shutter. It will then be seen that the front of the magazine is provided along its sides with two series of projecting teeth ; it is upon these teeth that the films inserted into the holder are supported. At one end of the magazine, which we shall call the top, is a button ; if this button be pushed from one side to the other, this movement will shift all the sorting teeth at the same time, so that they will occupy positions a little to one side of their former ones.

A film introduced into the magazine will then be supported by the sorting teeth, when these stand in the original positions; if this film be put into the holder with its notched corners towards the top end of the magazine. It will, however, fall past the sorting teeth, which pass through its notches, when the change button is moved to one side and the sorting teeth stand in the second position mentioned.

The process of filling the magazine is very simple, for the pressure-board has only to be removed, and the films inserted into the holder with the white film downwards, i.e. towards the an apparatus room, and workshop. At the back is another large room to be used for a natural history museum.

Every room is fitted with electric light and Ridge ventilation, which keeps the air pure even when filled with workers. The lecture theatre, which is capable of holding from 80 to 100 boys, is fitted with a solid slate table on brick piers, so that work can be done on it with the most delicate instruments without interference from the vibration of the floors. The fact that the rooms are all on the ground floor, gives the opportunity of putting all delicate instruments, such as balances, galvanometers, \&c., on brick pillars, and thus to get rid of any vibration whatsoever.

The main laboratory contains ten tables for elementary physical measurements, two for calorimetry, two for magnetism, and two for heat experiments. Each table has a cupboard containing the necessary apparatus, and an electric lamp giving direct illumination on the tables without shadow or glare in the eyes of the worker.

Of the two smaller laboratories, one is an optical room, which can, of course, be completely darkened, and is fitted with two optical tables and a heliostat, so as to use direct sunlight as often as possible.

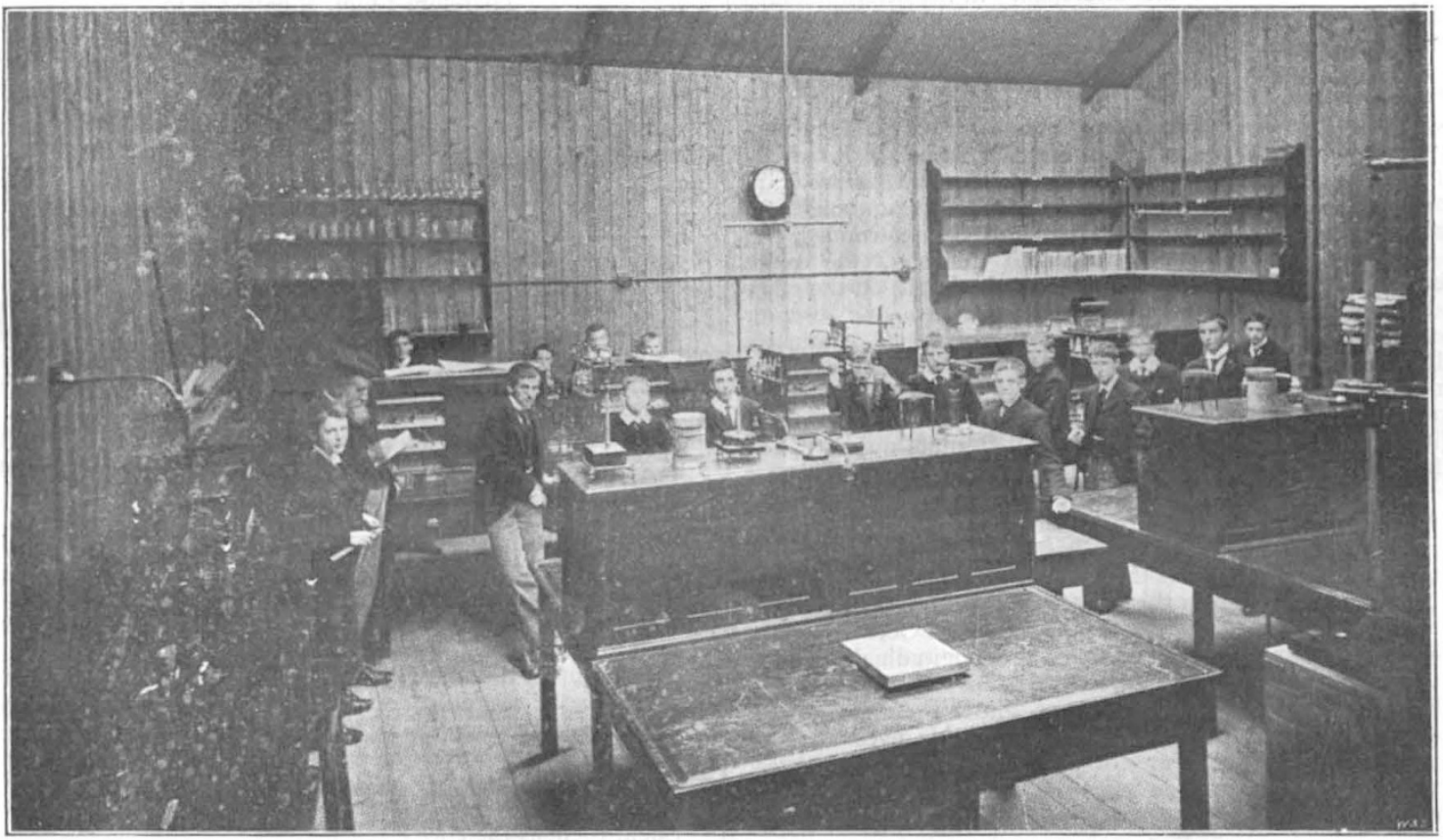

pointers, and eventually towards the lens. Should there remain in the magazine any unexposed films, with their backings, and it is merely required to add to their number, the additional films with their backings may be dropped into the holder by twos or threes, due care being taken that the alternate arrangement be maintained.

The whole process, although somewhat lengthy to describe. is in itself very simple and neat, and can be at once grasped by an examination of the holder itself in daylight.

\section{THE NEW NATURAL SCIENCE SCHOOLS $A T R U G B Y$.}

THIS new building for the physical part of natural science, which has recently been opened at Rugby School, is well worth a visit from any one engaged in teaching that subject. The building, owing to want of funds, is not at present of a permanent nature, being of the felt and matchboarding type, and in consequence has no pretensions to structural beauty; but when funds are forthcoming, no doubt the whole will be built in brick, and this will enable any alteration or improvement which may then be deemed necessary to be made. The building comprises a lecture room, a large laboratory, two small laboratories,
The other is the electricity room, containing two tables for frictional, and two for voltaic electricity, with cupboards, \&c., as in the main laboratory.

Provision has been made for a small engine and dynamo for electrical work, and these will no doubt be added in time.

The whole is under the charge of Mr. L. Cumming, to whom the arrangement is due, and who is certainly to be congratulated on the result.

Every boy who takes up natural science at Rugby not only goes through a course of lectures, but has also to do experimental work himself in the laboratory. This enables him to grasp the subject much more thoroughly, and to remember it much better than if he attended the lectures only. That this method has had excellent results, will be seen by the number of successes in natural science that Rugby has gained of late years in scholarship and other examinations.

\section{EVIDENCE OF A TWILIGHT ARC UPON THE PLANET MARS}

D URING last summer and autumn Mr. Douglass made at this observatory 34I micrometric measures of the diameters of Mars. In addition to their general value as micrometric measurements, these turn out to be of a peculiarly interesting NO. I 347 , VOL. 52$]$ 